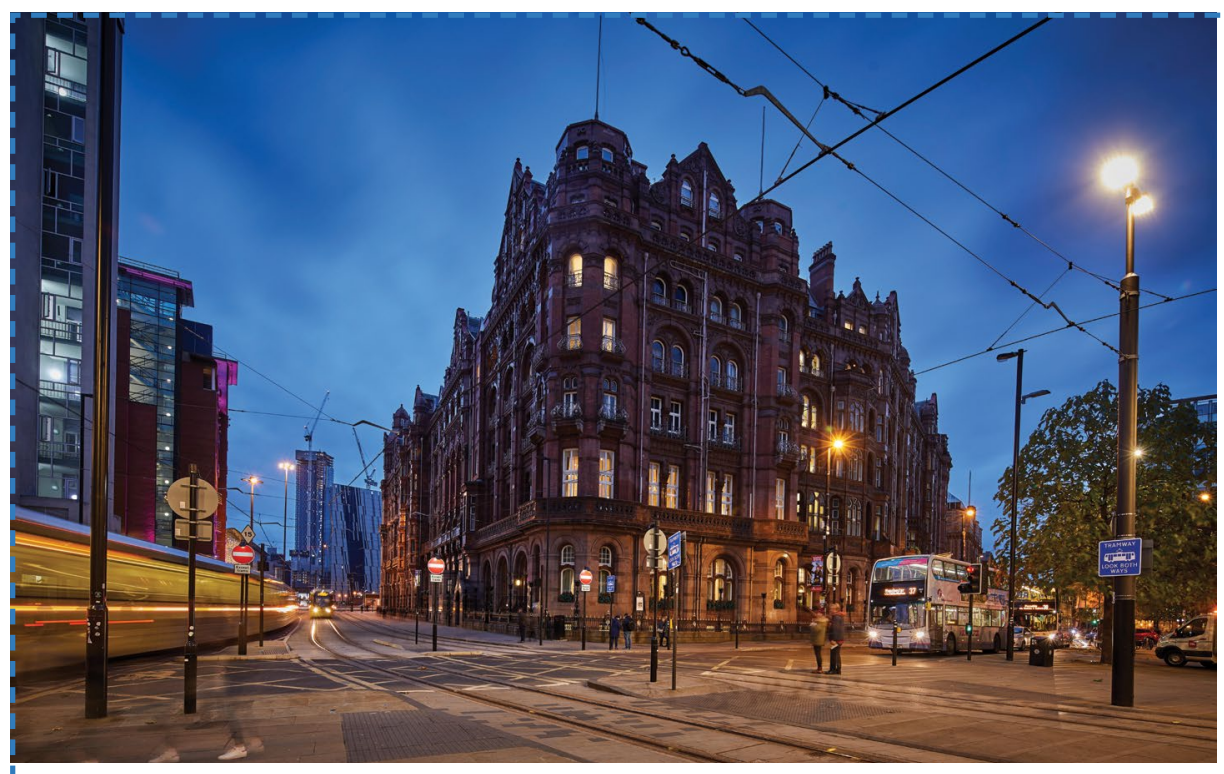

\section{BOS TO HOLD FIRST HYBRID ANNUAL CONFERENCE}

The British Orthodontic Society (BOS) have announced that this year's British Orthodontic Conference, to be held in the iconic Midland Hotel in Manchester on 16-18 September 2021, will be the event's first ever hybrid offering.

Following such an unusual year, the BOS would like to invite everyone with an interest in orthodontics - consultants, specialists, training grades, GDPs, therapists and nurses - to come along, listen to a fantastic programme live, visit Manchester, socialise and meet friends and colleagues again.

The hybrid element event will allow those delegates who, for whatever reason, can't travel, or overseas delegates, to be able to register and access the BOC lecture programme virtually, as well as attend a virtual trade exhibition and network with colleagues online.

The conference programme includes Phil Hammond (Private Eye's MD, physician, broadcaster, comedian and commentator on health issues), and the prestigious Northcroft Lecture will be presented by BOS President, Professor Jonathan Sandler. There will also be parallel sessions: 'Driving Private Practice,' 'So you want to know about Orthodontics' for aspiring orthodontists, and a two-day DCP programme.

David Waring, Chair of the British Orthodontic Conference Committee, said: 'We were so disappointed not to have a conference in 2020 and we have worked extremely hard to deliver a conference in 2021 that is doubly good! Everyone can book with confidence - if we have to make any changes or hold a purely virtual event, you will always be able to transfer to the online event and get the appropriate refund. We recognise the importance of flexibility when it comes to plans and hope this provides the reassurance colleagues need.

'We feel that we have something for all the team at this year's conference and look forward to welcoming everyone.'

Registration opened at the start of May for the 2021 British Orthodontic Conference - visit www.bos.org.uk/News-and-Events/ Events-Meetings to find out more and to book.

An early bird discount will be available for all bookings made before 23 July and a combined team rate is on offer too so that the whole team can attend, learn, and have fun.

\title{
DCPS ADVISED TO CHECK THEIR CPD HOURS
}

All dental care professionals (DCPs) have been advised to ensure they are on track to meet the minimum continuing professional development (CPD) requirements for maintaining General Dental Council (GDC) registration before the end of the CPD year on 31 July 2021. This includes the need to comply with the ten hours over two years rule and making an annual CPD statement.

The GDC's Enhanced CPD Scheme requires all dental professionals to complete a minimum of ten hours of verifiable CPD over each consecutive two-year period, including any two-years that span more than one CPD cycle. This means in one year a dental professional could do no CPD activity, but in the following year, they would need to complete ten hours of CPD to meet the requirements.

This rule has been introduced to help ensure CPD is spread out over the full five-year cycle, and is the reason dental professionals are asked to make a CPD statement each year at annual renewal time.

Dental professionals must meet these requirements to maintain their GDC registration. The only exception is those who are new onto the register, so have not yet started a CPD cycle. Dental professionals are advised to check the number of CPD hours they have logged last year on their eGDC account, and the number done so far this year, to ensure they are able to meet the minimum requirements.

If there is shortfall due to COVID-19, dental professionals are advised to do all that they can to be compliant by the end of the CPD year. However, if this proves not to be possible for reasons related to COVID-19, the GDC will take your exceptional circumstances into account. Dental professionals might also consider applying for a grace period if they need more time to complete your CPD,

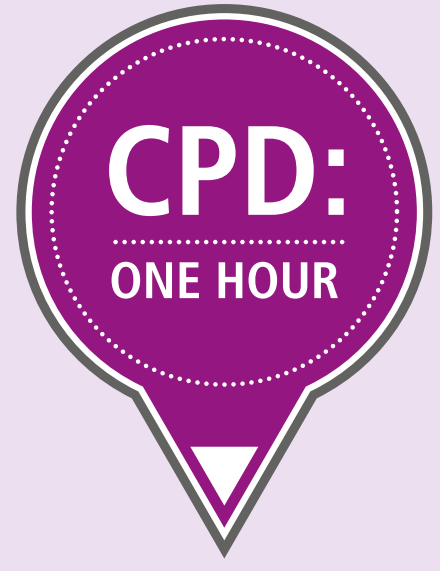

but this needs to be applied for in writing before the 31 July deadline.

Further guidance on CPD requirements and the rules of the Enhanced CPD scheme are available from the GDC website, which includes tools to help record and submit CPD. www.gdc-uk.org 